\section{O passado do futuro: uma análise diacrônica do ir + infinitivo no português europeu}

The past of future: a diachronic analysis of ir + infinitive in European Portuguese

Paulo Ângelo de ARAÚJO ADRIANO (UNICAMP) pauloangeloaa@gmail.com
ARAÚJO ADRIANO, Paulo Ângelo de. O passado do futuro: uma análise diacrônica do ir + infinitivo no português europeu. Entrepalavras, Fortaleza, v. 7, p. 132-150, ago./dez. 2017.

Resumo: Este trabalho é uma análise diacrônica da expressão do futuro do presente, no português europeu (PE). Especificamente, analisaramse 3 variantes do futuro, a saber, o (i) ir + infinitivo (vou comer), (ii) haver/ ter de + infinitivo (hei de comer), e (iii) futuro simples (comerei, poderei comer). Estudos anteriores sobre $\mathrm{O} \mathrm{PE}$ (HRICSINA, 2011) atestam um processo cíclico para a evolução do Tempo futuro, cuja expressão com a perífrase ir + infinitivo já estaria presente desde o século XIII (LIMA, 2001). Este estudo tem como objetivo, então, observar o percurso da realização do Tempo futuro no português europeu, nos séculos XVIII - XIX, partindo da hipótese de que, inicialmente, a estrutura ir + infinitivo era usada quando a proposição expressa pelo verbo principal se concretizaria imediatamente após a enunciação e, em seguida, a mesma estrutura passou a denotar futuro, ou seja, um evento posterior em relação ao momento da fala. Para tanto, analisaram-se peças de teatro portuguesas (entremezes) entre 1783-1877, disponíveis no acervo do Laboratório de História do Português (LaborHistórico).

Palavras-chave: Diacronia. Expressão do futuro. Português europeu. 
Abstract: The present work is a diachronic analysis of the future indicative's expression in European Portuguese (EP). Specifically it analyzes 3 variants of the future Tense, namely: (i) vou + infinitive (vou comer), (ii) haver/ter + de + infinitive (hei de comer), and (iii) simple future (comerei, poderei comer). Previous studies about EP (HRICSINA, 2001) certify a cyclic process for the future Tense evolution, whose expression with the periphrasis ir + infinitive has been existed since the XIII century (LIMA, 2001). The study aims to observe the course of the future tense realization in centuries XVIII - XIX in EP, from the hypothesis that initially the structure ir + infinitive was used when the expressed proposition by the main verb would concretize immediately after the enunciation and, after that, the same structure has transitioned to denote future Tense, in other words, a posterior event in relation to the moment of speech. For that, the corpus was based on EP dramas from 1783-1877, available in the collection at Laboratory of Portuguese History (LaborHistórico).

Keywords: Diachrony. Future expression. European Portuguese.

\section{Introdução}

Assim como em outras línguas românicas, o português europeu (PE) passou por um período cíclico no que se refere à estrutura do Tempo ${ }^{1}$ futuro. Vindo do latim, tal Tempo foi originado a partir de uma forma perifrástica, habere, que se tornou um morfema temporal (-ei), aglutinando-se, posteriormente, ao verbo principal (louvarei). Esse processo deu origem ao futuro sintético. Em coocorrência à essa forma, entrou no sistema o verbo ir, que passou a ser reanalisado como a estrutura para o Tempo futuro, fato já atestado na literatura (cf. FLEISCHMAN, 1982; ROBERTS; ROUSSOU, 2003). Os mesmos autores mostram que ir sofreu gramaticalização, deixando o seu sentido de movimento no espaço físico, para também atribuir movimento no espaço do tempo.

A partir de um corpus do português europeu, o que o presente trabalho traz de novidade é dar uma maior atenção ao verbo ir, em estruturas de ir + infinitivo, com o objetivo de observar quais foram as mudanças ao longo do tempo que fizeram com que o verbo ir viesse a ser "promovido" a auxiliar de Tempo futuro, no que se refere ao seu deslocamento temporal, no $\mathrm{PE}^{2}$. Em uma primeira observação dos dados, observou-se que o verbo ir era frequentemente usado, nas peças

\footnotetext{
${ }^{1}$ Neste texto, diferencia-se tempo, minúsculo, de Tempo, maiúsculo. Ao primeiro atribui-se as noções de tempo físico, cujos eventos são organizados numa linha temporal. Já o segundo é usado para a categoria gramatical, que é marcada pela flexão verbal expressando quando, no tempo, um evento ocorreu.

${ }^{2}$ A escolha por trabalhar com dados do PE é motivada pela intenção de se trabalhar com o PB, num outro momento, e verificar, a partir do mapeamento feito aqui, se existe alguma influência do PE no PB, ou se as mesmas mudanças ocorreram de forma semelhante nas duas línguas, no que se refere às estruturas de futuro.
} 
v. 7 (2)

$132-150$ ago/dez 2017

analisadas, para expressar uma ação que acontecia já no momento da fala, no presente. Ou seja, a promoção do verbo ir como auxiliar poderia ter sido favorecida pela gradação da sua temporalidade - inicialmente expressando um evento [- distante], para depois expressar um [+ distante], ambos em relação à fala. Dessa maneira, o trabalho é norteado pela hipótese de que, num primeiro momento, o verbo ir significava uma ação imediatamente após, ou até durante, a enunciação e, mais tarde, uma ação mais distante em relação ao momento da fala, já com sentido de futuro.

\section{O processo cíclico do Tempo futuro}

Hricsina (2011), ao analisar a evolução das formas de futuro desde o indo-europeu até o português moderno, constata que o Tempo futuro passou por um processo de forma perifrástica $>$ forma sintética $>$ forma perifrástica. No latim clássico, a autora mostra que havia dois tipos de estrutura para marcação de futuro: (i) o sufixo $-b$, para a $1^{\mathrm{a}} \mathrm{e}$ $2^{\text {a }}$ conjugação, como em laudabo, monebo; (ii) o sufixo - e e -a, como audiam, audies. Oliveira, (2006) já inclui outra forma para o futuro no latim: o futuro arcaico, como faxo e capso - que remontavam aos futuros em -so do grego e do osco-umbro e em -syá do sânscrito.

No latim vulgar, por outro lado, essas formas caíram em desuso, e as gradações modais ganharam mais força, expressando dubidatividade, volitividade, desideratividade e hipoteticidade. Isso significa que, além da forma sintética - bo que ainda estava no sistema, havia outras formas perifrásticas para expressar futuridade. Como exemplo, havia a combinação de -urus, futuro ativo particípio, com as formas de sum: amaturus sum, eram, ero (cf. OLIVEIRA, 2006; HRICSINA, 2011). Segundo Fleischman (1982), tal construção expressava iminência, intencionalidade, destino, posterioridade, ou seja, expressava aspecto. De acordo com a autora, à medida que tais expressões indicavam aspecto prospectivo, elas adquiriam traço ulterior, passando a indiciar a forma de futuro.

Além dessa forma perifrástica, encontrava-se, ainda no latim vulgar, uma estrutura composta por habere, no presente, com infinitivo, que, no século IV, carregou consigo o valor de futuro puro, pois inicialmente marcava modal deôntico (cantare habeo = hei de cantar, devo cantar) e, segundo Fleischman (1982), depois, para o Português e outras línguas românicas, usado como morfema temporal (louvar- 
ei). Por volta do século VII, a perífrase se compactou, aglutinando-se ao verbo principal. Dessa forma, surgiu o futuro românico sintético: cantare habeo > cantare hei > cantarei (pt.), chanterai (fr.), cantaré (esp.), canteró (it.) (OLIVEIRA, 2006).

Nesse cenário, Roberts e Roussou (2003) fazem uma análise e assumem que o futuro românico sintético foi originado de uma construção perifrástica no latim: no francês, por exemplo, a conjugação do avoir - habere - é comparada à conjugação do futuro nessa língua (1), igualmente observado em português (2) com o haver - habere:

(1) Avoir (habere): ai; as; a; avons; avez; ont

Futuro no FR: chanterai; chanteras; chantera; chanterons; chanterez; chanteront.

(2) Haver (habere): hei; hás; há; havemos; haveis; hão.

Futuro no PT: cantarei; cantarás; cantará; cantaremos; cantareis; cantarão.

Assim, os autores dizem que o verbo pleno, lexical, habere no latim foi reanalisado como terminação de futuro nas línguas românicas, como observado em (1) e (2). Em relação à perífrase com ir + infinitivo, Santos (2002) afirma que tal construção surgiu no espanhol, no francês e no português, a partir dos séculos XIII e XIV e passou a ser generalizada na fala durante o séc. XVI e XVIII. Segundo a autora, o presente do indicativo era comum de ser usado com sentido futuro já durante o Império Romano.

Dessa maneira, parece que, em todas as línguas românicas, o Tempo futuro passou pelo mesmo processo cíclico: ora estruturado por uma forma sintética, ora por uma forma analítica.

\section{O Tempo futuro no PE e no PB: cenário atual}

Sobre o português moderno, foram encontradas três variantes ${ }^{3}$ para a forma de futuro (cf. HRICSINA, 2011; OLIVEIRA, 1985) no português europeu. A saber, o futuro simples; o perifrástico, formado por ir +

\footnotetext{
${ }^{3}$ Não se sabe se a estrutura formada pelos modais "poder" e "dever" + infinitivo são variantes para a expressão de futuro em PE. Drzazgowska (2012, p. 110-111) considera tais estruturas como perifrásticas, porém atribui-lhes outro significado, não deixando claro se expressam ou não futuro:

(i) dever + infinitivo, que exprime obrigação moral, material, lógica e também exprime probabilidade;

(ii) poder + infinitivo, que exprime possibilidade lógica, física ou moral.
} 
v. 7 (2)

$132-150$ ago/dez 2017

infinitivo; e o presente, respectivamente, exemplificados (HRICSINA, 2011, p. 176-177):

(3) Bébé, que terá 19 ou 20 anos, negligentemente estirada num "maple", folheia uma revista ilustrada e fuma;

(4) mas acontece que o único dinheiro que recebo é o que no fim do mês vou buscar lá abaixo, à tesouraria;

(5) Então nós amanhã falamos e acertamos os pormenores.

Em relação à forma de presente, Oliveira, (1985) levanta a hipótese de que o presente só marca posterioridade quando acompanhado de um advérbio de Tempo futuro.

Do outro lado do oceano, no PB, 5 formas de futuro foram atestadas (cf. GIBBON, 2000; GONÇALVES, 2013; OLIVEIRA, 2006; 2012; ARAÚJO ADRIANO, 2014; 2016). A saber, (i) forma sintética com frequência muito baixa; (ii) forma perifrástica com ir + infinitivo; (iii) forma perifrástica com modal + infinitivo; (iv) forma presente do indicativo e (v) forma perifrástica com ir + infinitivo + gerúndio (vou estar comendo).

\section{O futuro no PE e no PB: alguns estudos diacrônicos}

Numa perspectiva diacrônica, para o português europeu, Lima (2001) analisou textos literários medievais e mostrou que, no século XVIII, o futuro simples era usado em uma frequência maior que a forma perifrástica, talvez, segundo o autor, em razão do nível de formalidade encontrado nos gêneros analisados, mesmo em cartas pessoais. Segundo Lima (2001), as primeiras ocorrências de ir + infinitivo são datadas do séc. XIII, mas com um "teor" de futuro, somente no século seguinte:

(6) E há em ella muytos ryos, dos quais o primeiro he o Ebro que vay entrar e no mar terreno. (Crônica Geral de Espanha, Século XIV)

Hricsina (2011), para mostrar o processo cíclico do futuro no PE, apresenta o português antigo (séc. XII) contendo haver de + infinitivo e a forma sintética para a expressão de futuro. Já para o português moderno, propõe queda daquelas duas formas, com aparição das estruturas ir + infinitivo e a forma de presente. 
Oliveira (2006), também em uma perspectiva diacrônica, analisou um corpus do $\mathrm{PB}$ e sugeriu que ir sofreu um processo de gramaticalização, denotando sentido de futuro, não só de movimento, que já estava presente no século XIV, instalando-se como auxiliar no século XVI e ultrapassando o futuro simples, no século XX.

Segundo a autora, o futuro simples foi a variante mais utilizada desde o séc. XIII, concorrendo até o sec. XIX com a forma haver de + infinitivo. Foi no século XX que seu lugar foi ocupado pela perífrase encabeçada pelo verbo ir + infinitivo. A autora ainda diz que, no séc. XVII, começou a disputa entre as formas perifrásticas formadas por haver de + infinitivo e ir + infinitivo, superando aquela forma já no século XVIII e, no século XX, o futuro simples.

\section{A teoria da mudança linguística}

Este trabalho parte de uma perspectiva da gramática gerativa para o fenômeno da mudança linguística. Para Chomsky (1986), uma criança adquire sua língua materna a partir da língua a qual ela é exposta, uma vez que a espécie humana possui um componente biológico, geneticamente determinado, capaz de compreender, produzir sentenças infinitas por meio de regras finitas. Ou seja, a criança nasce com uma Faculdade da Linguagem, que se desenvolve de um estado inicial $\left(\mathrm{F}_{0}\right)$ a um estado final $\left(\mathrm{F}_{\mathrm{f}}\right)$, cuja gramática se aproxima à gramática do adulto (cf. CHOMSKY, 1986, 1995).

Devido ao fato de que cada criança tem uma experiência linguística individual, única, Chomsky $(1986,1995)$ propõe que cada uma possui uma língua-I (individual, interna, intensional), moldada pela experiência linguística, pela língua-E (externa) dos pais. Dessa maneira, a partir do output linguístico dos pais, a criança é capaz de fixar os parâmetros da língua-alvo. Nesse contexto, uma mudança linguística ocorre, segundo Lightfoot (1991), quando uma estrutura é reanalisada, e, por isso, sua frequência é reduzida em detrimento de uma estrutura inovadora. Dessa forma, a língua-E a qual a criança tem acesso será estruturada de forma distinta quando da aquisição dos pais. Ou seja, a reanálise de uma estrutura altera o tipo de evidência que a criança encontra no processo de aquisição, tendo sua língua-I diferente da língua-I da geração anterior.

Segundo Antonelli (2011), seria natural pensar que o surgimento de um novo sistema linguístico, a mudança em si, ocorresse quando as 
v. 7 (2)

$132-150$ ago/dez 2017

formas inovadoras fossem produzidas, isto é

quando as formas linguísticas novas de fato aparecem no ambiente linguístico, ainda que em taxas menos elevadas do que as formas antigas. Ao longo do tempo, em decorrência do processo de competição de gramáticas, apenas uma das formas em variação é que permanecerá no repertório linguístico dos falantes (ANTONELLI, 2011, p. 18).

A partir do exposto, na próxima seção, faz-se uma descrição do corpus estudado, bem como uma apresentação dos critérios adotados para a análise dos dados e, ainda, a exposição do envelope de variação.

\section{Metodologia}

Corpus

Os dados empíricos da pesquisa fazem parte do acervo do corpora do Laboratório de História do Português, da Universidade Federal do Rio de Janeiro. O corpus de análise é composto por entremezes ${ }^{4}$ portugueses entre os séculos XVIII - XIX. Para o presente trabalho, escolheu-se por analisar essas peças de teatro portuguesas, por, de certa forma, representarem mais fielmente a fala daquele período, uma vez que, de acordo com Lopes (2004, p. 7), "os entremezes apresentavam temas simplórios e personagens populares do cotidiano da época".

O critério de escolha das peças foi o período em que elas foram escritas. Assim, com o objetivo de mapear, de maneira geral, a variação da forma de futuro ao longo do tempo, analisaram-se seis peças dos anos de 1783, 1786, 1790, 1794, 1808, 1877, proporcionando um envelope de dados num período de aproximadamente um século. Esse corpus é composto por 21.414 palavras, havendo nele 204 ocorrências de futuro. Na tabela abaixo, encontra-se o nome das peças, bem como o número de ocorrência de futuro em cada uma.

Tabela 1 - Distribuição das peças de teatro no corpus

\begin{tabular}{|c|l|c|c|}
\hline Ano da peça & \multicolumn{1}{|c|}{ Nome da peça } & $\begin{array}{c}\text { Sigla de } \\
\text { referência }\end{array}$ & $\begin{array}{c}\text { Ocorr. } \\
\text { de } \\
\text { futuro }\end{array}$ \\
\hline 1783 & Novo entremez intitulado a escola do amor & P1783 & 26 \\
\hline 1786 & $\begin{array}{l}\text { Novo entremez intitulado as loucuras da } \\
\text { velhice }\end{array}$ & P1786 & 25 \\
\hline
\end{tabular}

4 "Breve composição dramática de um só ato, de gênero burlesco, geralmente no intervalo ou no fim de uma peça de longa duração" - definição retirada do Dicionário Priberam da Língua Portuguesa (Disponível em: https://priberam.pt/dlpo/entremezes. Acesso em 20 set. 2017.) 


\begin{tabular}{|c|l|c|c|}
\hline 1790 & $\begin{array}{l}\text { Novo, e divertido entremaz intitulado a } \\
\text { grande dedordem de huma velha com hum } \\
\text { peralta }\end{array}$ & P1790 & 50 \\
\hline 1794 & $\begin{array}{l}\text { Novo entremez intitulado a dama } \\
\text { prezumida por querer andar A'moda }\end{array}$ & P1794 & 34 \\
\hline 1808 & $\begin{array}{l}\text { Novo entremez intitulado o gallego lorpa, e } \\
\text { os tolineiros }\end{array}$ & P1808 & 36 \\
\hline 1877 & $\begin{array}{l}\text { Rato, 22, 30 } \text {, esquerdo por Luiz Quirino } \\
\text { Chaves }\end{array}$ & P1877 & 33 \\
\hline Total & - & - & 204 \\
\hline
\end{tabular}

Os traços

Para análise dos dados, traços semânticos e morfológicos foram utilizados, a saber, [ \pm distante], [ \pm futuridade], e [ \pm regular $]$, traços esses baseados em Gibbon (2000) e Oliveira (2006).

O traço [ \pm distante] foi considerado com o objetivo de verificar, ao longo do tempo, quando o ir no presente (vou) passou a ter um traço [+ distante]. Isso porque, como já mencionado, este trabalho parte da hipótese de que (i) inicialmente o verbo ir era usado em contextos em que a proposição seria executada em um momento [- distante] em relação ao momento da enunciação e, (ii) num segundo momento, tal construção receberia um traço [+ distante] em relação ao momento da fala, trazendo, assim, consigo uma noção temporal futura. Abaixo, há o traço exemplificado:

(7) Cazarás com o castigo, que prometto de te dar. (P1783) [+ distante]

(8) Descanço um instantinho, e depois vou pôr-me ao brazeiro. (P1877) [+ distante $]$

(9) Mas ai que naõ estou em mim, vendo aquelles Estafermos, vou chamar alguns visinhos, que me livrem deste enleio. (P1783) [- distante].

O traço [ \pm futuridade] é a presença ou ausência de uma partícula, advérbio, locução adverbial, temporal. Tal escolha para a análise dos dados foi feita para verificar se, pelo fato de o verbo ir estar no presente, nas perífrases verbais de futuro (vou fazer), é necessária a presença de um advérbio temporal para denotar futuro.

Seguem os exemplos: 
v. 7 (2)

$132-150$ ago/dez 2017

(10) Agora veja o que faz, cuidado, e mais cuidado, estudeme sem descuido, depois verei como vai. V. (P1786) $[+$ futuridade]

(11) Pobre Velha, ha de ficar xupando no dedo, confesso a verdade. (P1790) [-futuridade]

Outro traço também considerado foi a regularidade dos verbos: [ \pm regulares]. É importante apontar que a análise foi feita sempre em relação ao verbo principal, tanto quando expresso sem locução (farei), quanto quando expresso em uma locução (hei de fazer; vou fazer).

A classificação da regularidade foi baseada na definição de Camara Jr. (1970; 1976), quando mostra que os verbos irregulares apresentam mais de um radical, entre a forma de imperfeito e de perfeito. Isto é, quando houver um radical para a forma de imperfeito e outro radical para a forma de perfeito, o verbo será irregular ${ }^{5}$. Assim, toda a classificação é baseada no radical do verbo, pois, segundo o autor, "a mudança no radical é que é verdadeiramente importante e cria uma série de padrões morfológicos verbais" (CAMARA JR., 1970, p. 111).

Como exemplos, há:

(12) O Santo Ceo favoreça nossos, constantes extremos, pois por elle portegidos sempre seremos felices. (P1790) [regular]

(13) Naõ tenho defluxo, já estou rija; inda hei de viver muitos annos, e todos haõ de ser na companhia do meu requinho noivo, do meu maridinho bello, a quem vossê com todo o respeito ha de chamar seu Pai, tem percebido? (P1790) [+ regular]

\footnotetext{
5 Segundo Camara Jr. (1970; 1976), os verbos irregulares são 17: caber, dar, dizer, estar, haver, fazer, ir, poder, pôr, prazer, querer, saber, ser, ter, trazer, ver, vir. Tal classificação ocorreu a partir da diferença do radical na forma de perfeito (presente, pretérito imperfeito, futuro do presente, futuro do pretérito, no modo indicativo, e presente do subjuntivo) e imperfeito (pretérito perfeito, pretérito mais-que-perfeito, no modo indicativo e pretérito imperfeito e futuro no modo subjuntivo). Como exemplo, o verbo "ver" tem sua conjugação em "vês", "vi", "vejo", apresentando mais de um radical para a forma de perfeito e imperfeito.
} 
As variantes

Para a análise dos dados, foram quantificadas ${ }^{6}$ as ocorrências da expressão de futuro, sendo classificadas em: (i) futuro simples (comerei, irei comer, haverei de comer); (ii) ir + infinitivo (vou comer); e (iii) haver/ter de + infinitivo (hei de comer, tenho de comer). Foram coletadas também locuções verbais com o verbo auxiliar flexionado na forma canônica do Futuro Simples, que foram incluídas na variante Futuro Simples. Assim, foram consideradas todas as formas de futuro flexionado, mesmo em locuções verbais como:

\section{(14) Por onde poderei fugir? (P1877)}

\section{Resultados e Discussões}

Das peças

Na Tabela 2, há os resultados ${ }^{7}$ gerais das análises feitas nas peças, levando em consideração o envelope das variantes.

Tabela 2 - Dados gerais das Peças de Teatro

\begin{tabular}{|c|c|c|c|c|c|c|c|c|c|c|c|c|c|c|}
\hline \multirow{2}{*}{ Variantes } & \multicolumn{2}{|c|}{ P1783 } & \multicolumn{2}{|c|}{ P1786 } & \multicolumn{2}{|c|}{ P1790 } & \multicolumn{2}{c|}{ P1794 } & \multicolumn{2}{c|}{ P1808 } & \multicolumn{2}{|c|}{ P1877 } & \multicolumn{2}{|c|}{ Total } \\
\cline { 2 - 17 } & $N^{\mathrm{O}}$. & $\%$ & $\mathrm{~N}^{\mathrm{O}}$ & $\%$ & $\mathrm{~N}^{\mathrm{O}}$ & $\%$ & $\mathrm{~N}^{\mathrm{O}}$ & $\%$ & $\mathrm{~N}^{\mathrm{O}}$ & $\%$ & $\mathrm{~N}^{\mathrm{O}}$ & $\%$ & $\mathrm{~N}^{\mathrm{O}}$ & $\%$ \\
\hline I+Inf & 7 & 27 & 4 & 16 & 6 & 12 & 2 & 6 & 3 & 8 & 16 & 49 & 38 & 19 \\
\hline FS & 11 & 42 & 15 & 60 & 22 & 44 & 20 & 59 & 24 & 67 & 12 & 36 & 104 & 51 \\
\hline H/T+Inf & 8 & 31 & 6 & 24 & 22 & 44 & 12 & 35 & 9 & 25 & 5 & 15 & 62 & 30 \\
\hline Total & 26 & 100 & 25 & 100 & 50 & 100 & 34 & 100 & 36 & 100 & 33 & 100 & 204 & 100 \\
\hline
\end{tabular}

Da análise da Tabela 2, pode-se perceber que no ano 1783, a maior frequência de futuro foi com a forma de futuro simples, com $42 \%$. Em seguida, está a forma haver/ter de + infinitivo, com 31\%. Somente $27 \%$ dos casos foram com ir + infinitivo. Quando se analisa o ano 1786, há preferência pela forma sintética, $60 \%$, seguida pela forma haver + infinitivo, $24 \%$, e por último a estrutura ir + infinitivo, computada em 16\% dos casos. Já em 1790, há uma concorrência entre o Futuro Simples e haver/ter de + infinitivo (44\% cada), sendo a menor ocorrência de $12 \%$, para a perífrase com ir. Em 1794, a concorrência entre a forma

\footnotetext{
${ }^{6}$ Como o objetivo do trabalho é mostrar a reanálise da estrutura ir + infinitivo, apresentar-se-ão no texto somente as tabelas, cujos dados são do próprio ir + infinitivo. Porém, far-se-á a análise das outras variantes.

${ }^{7}$ Para a tabela, as variantes $I r$ + infinitivo, Futuro Simples e Haver/ter de + infinitivo são, respectivamente, I+Inf, FS e H/T + Inf.
} 
v. 7 (2)

$132-150$ ago/dez 2017

sintética e a forma com haver permanece, respectivamente 59\% e 35\%; há pouca ocorrência de ir + infinitivo, 6\%. Em 1808, o uso de haver + infinitivo caiu, atingindo $25 \%$, enquanto a forma sintética permanece como a mais usada, 67\%. Uma "mudança" parece ficar evidente em 1877, quando a forma haver/ter de + infinitivo cai bruscamente, 15\%, dando espaço para a forma ir + infinitivo, 49\%, sobrepondo até mesmo a forma sintética, com 36\%.

Ao total, no corpus das peças, percebe-se uma preferência pela forma sintética, com 51\% dos casos. Com 30\%, está a forma haver/ter de + infinitivo e, por último, a forma ir + infinitivo, 19\%. Embora o número de ocorrências de ir + infinitivo seja pequeno em relação aos demais, é possível observar a preferência, já no fim do séc. XIX, por tal forma. Além disso, pode-se também observar a queda, ao longo do tempo, do uso do haver/ter de + infinitivo. O Gráfico 1 ilustra esses dados:

Gráfico 1 - Formas de futuro ao longo do tempo

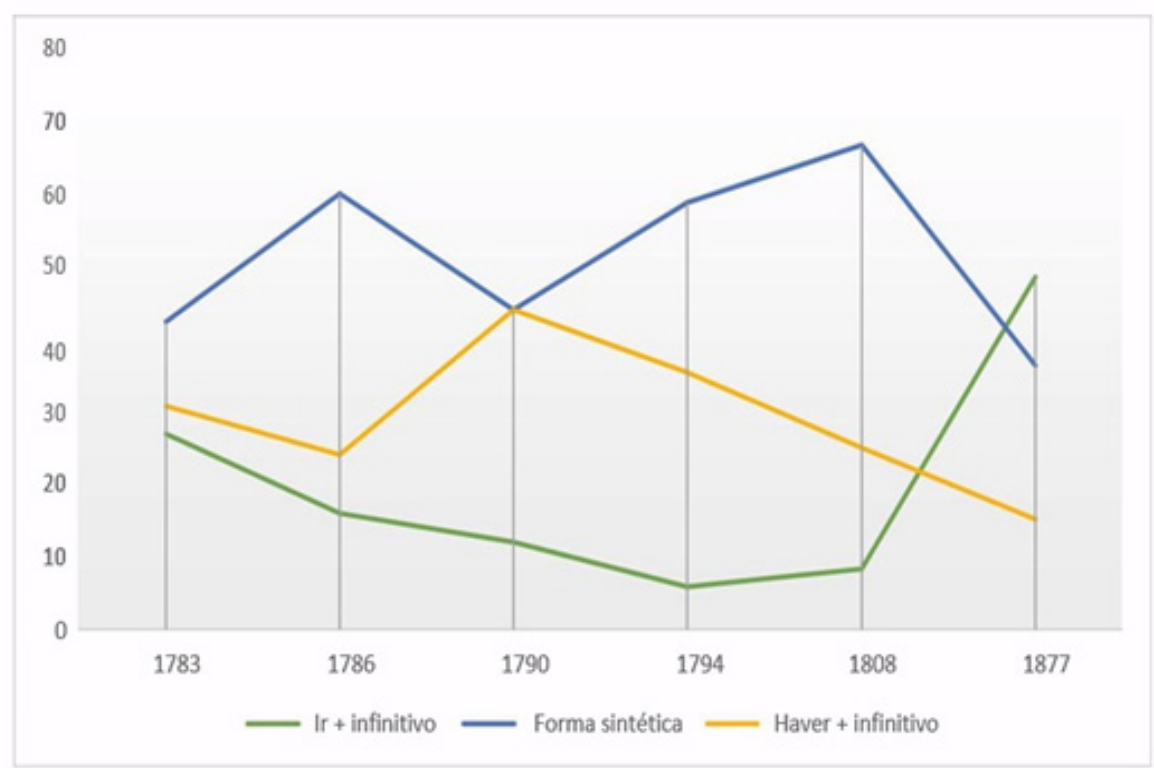

Controle do traço [ \pm regularidade]

Em relação à regularidade dos verbos, o verbo principal com o traço [- regular] em Futuro Simples ocorreu 37\% dos casos, enquanto $62 \%$ eram portadores do traço [+ regular] (15 e 16). O mesmo ocorre com ir + infinitivo, em que, na maior parte das ocorrências, o verbo principal tinha o traço [+ regular], $57 \%$, e $43 \%$ com o traço [- regular], como observado na Tabela 3. Haver/ter de + infinitivo, por outro lado, foi mais utilizado em contexto de [- regularidade], computando 56\% dos casos. 
Tabela 3 - Ir + Infinitivo e o traço [ \pm regularidade]

\begin{tabular}{|c|c|c|c|c|c|c|c|c|c|c|c|c|c|c|}
\hline \multicolumn{15}{|c|}{ Ir + Infinitivo } \\
\hline \multirow{2}{*}{ Traço } & \multicolumn{2}{|c|}{ P1783 } & \multicolumn{2}{|c|}{ P1786 } & \multicolumn{2}{|c|}{ P1790 } & \multicolumn{2}{|c|}{ P1794 } & \multicolumn{2}{|c|}{ P1808 } & \multicolumn{2}{|c|}{ P1877 } & \multicolumn{2}{|c|}{ Total } \\
\hline & $\mathrm{N}^{\mathrm{O}}$. & $\%$ & $\mathrm{~N}^{\mathrm{O}}$ & $\%$ & $\mathrm{~N}^{\mathrm{O}}$ & $\%$ & $\mathrm{~N}^{\mathrm{O}}$ & $\%$ & $\mathrm{~N}^{\mathrm{O}}$ & $\%$ & $\mathrm{~N}^{\mathrm{O}}$ & $\%$ & $\mathrm{~N}^{\mathrm{O}}$ & $\%$ \\
\hline [+ regul.] & 4 & 57 & 1 & 25 & 3 & 50 & 0 & 0 & 2 & 67 & 12 & 75 & 22 & 58 \\
\hline [- regul.] & 3 & 43 & 3 & 75 & 3 & 50 & 2 & 100 & 1 & 33 & 4 & 25 & 16 & 42 \\
\hline Total & 7 & 100 & 4 & 100 & 6 & 100 & 2 & 100 & 3 & 100 & 16 & 100 & 38 & 100 \\
\hline
\end{tabular}

Esses resultados podem indicar que a regularidade do verbo não é uma motivação para a não flexão do verbo, uma vez que tanto o Futuro Simples, quanto ir + infinitivo foram mais utilizados em [+ regularidade]. Logo, a queda da flexão parece não ser diretamente proporcional à regularidade do verbo principal.

(15) Ha de ser um monstro de valor. (P1877) [- regularidade]

(16) Naõ tenho defluxo, já estou rija; inda heide viver muitos annos, e todos haõ de ser na companhia do meu requinho noivo, do meu maridinho bello, a quem vossê com todo o respeito ha de chamar seu Pai, tem percebido? (P1790) [+ regularidade]

(17) Mana, vamos ver se vimos os nossos amantes. (P1786) [regularidade]

(18) Maldita; por teu castigo, hasde fazer tudo de novo. (P1794) [- regularidade]

Controle do traço [ \pm distante]

Com o objetivo de observar o período em que ir + infinitivo passou a ter uma "essência" de futuro, analisaram-se os dados também levando em consideração o traço [ \pm distante].

Tabela $4-I r+$ infinitivo e o traço $[ \pm$ distante $]$

\begin{tabular}{|c|c|c|c|c|c|c|c|c|c|c|c|c|c|c|}
\hline \multirow{3}{*}{ Traço } & \multicolumn{14}{|c|}{ Ir + Infinitivo } \\
\hline & \multicolumn{2}{|c|}{ P1783 } & \multicolumn{2}{|c|}{ P1786 } & \multicolumn{2}{|c|}{ P1790 } & \multicolumn{2}{|c|}{ P1794 } & \multicolumn{2}{|c|}{ P1808 } & \multicolumn{2}{|c|}{ P1877 } & \multicolumn{2}{|c|}{ Total } \\
\hline & $\mathrm{N}^{\mathrm{O}}$. & $\%$ & $\mathrm{~N}^{\mathrm{O}}$ & $\%$ & $\mathrm{~N}^{\mathrm{O}}$ & $\%$ & $\mathrm{~N}^{\mathrm{O}}$ & $\%$ & $\mathrm{~N}^{\mathrm{O}}$ & $\%$ & $\mathrm{~N}^{\mathrm{O}}$ & $\%$ & $\mathrm{~N}^{\mathrm{O}}$ & $\%$ \\
\hline [+ dist. $]$ & 0 & 0 & 0 & 0 & 2 & 33 & 0 & 0 & 1 & 33 & 8 & 50 & 11 & 29 \\
\hline [-dist.] & 7 & 100 & 4 & 100 & 4 & 67 & 2 & 100 & 2 & 67 & 8 & 50 & 27 & 71 \\
\hline Total & 7 & 100 & 4 & 100 & 6 & 100 & 2 & 100 & 3 & 100 & 16 & 100 & 38 & 100 \\
\hline
\end{tabular}


v. 7 (2)

$132-150$ ago/dez 2017

Em relação ao Futuro Simples, 91\% dos casos ocorreram em traço [+ distante] (19), o que já era esperado, uma vez que tal estrutura denota um futuro canônico, isto é, [+ distante] em relação ao momento da fala. Somente 9\% foi em contexto [ - distante], como em (20). O mesmo ocorreu com haver/ter de + infinitivo, com que 92\% dos casos foi [+ distante] (21), restando somente $8 \%$ para o outro traço, com em (22).

(19) Pobre Lambuza! que mais te succederá hoje? (P1808) [+ distante]

(20) Que Diabo diz elle? que naõ presta? ás contas fallaremos: se for taõ prompto em pagar, como em dar á taramela, vale por trinta: mas eu sempre arrenego destes amigos, que dizem muitos Latinorios. (P1808) [- distante]

(21) Naõ póde tardar hum instante, V.m. hade advertir, que só para o toucador he percizo a estas Senhoras infinito tempo. (P1794) [+distante]

(22) Oh Senhor Mestre estimado, ha de me tirar da duvida em que estou emcasquetada, diga, este caldeiraõ está aqui no seu lugar? (P1786) [- distante]

É interessante notar o exemplo (20), em que o Futuro Simples expressa [- distante] em relação ao momento da fala. Isso, porque, na peça $\mathrm{P} 1808$, havia uma discussão sobre quem iria pagar a conta, após uma refeição, e (20) retrata que o evento de "falar sobre as contas" se deu logo após tal enunciação, marcada, enfaticamente, até mesmo, no texto, pelos dois pontos em seguida.

A Tabela 4 mostra a evolução do ir + infinitivo em relação ao traço $[ \pm$ distante]; sendo possível observar também que, até o fim do séc. XVIII, essa estrutura era somente condicionada pelo traço [distante], denotando sua forma de presente (23). Porém, em 1808, início do séc. XIX, ir + infinitivo começa a ter traço [+ distante], 33\% (24), aparentando uma forma de futuro. É possível notar também que, em 1790, tal traço, mesmo que com baixa frequência, já se fazia presente. Em 1877, há uma clara coocorrência do traço [+ distante], 50\%, com o [-distante], também 50\%. O Gráfico 3 ilustra essas informações. 
Gráfico 3 - Coocorrência de Ir + infinitivo pelo traço [ \pm distante]

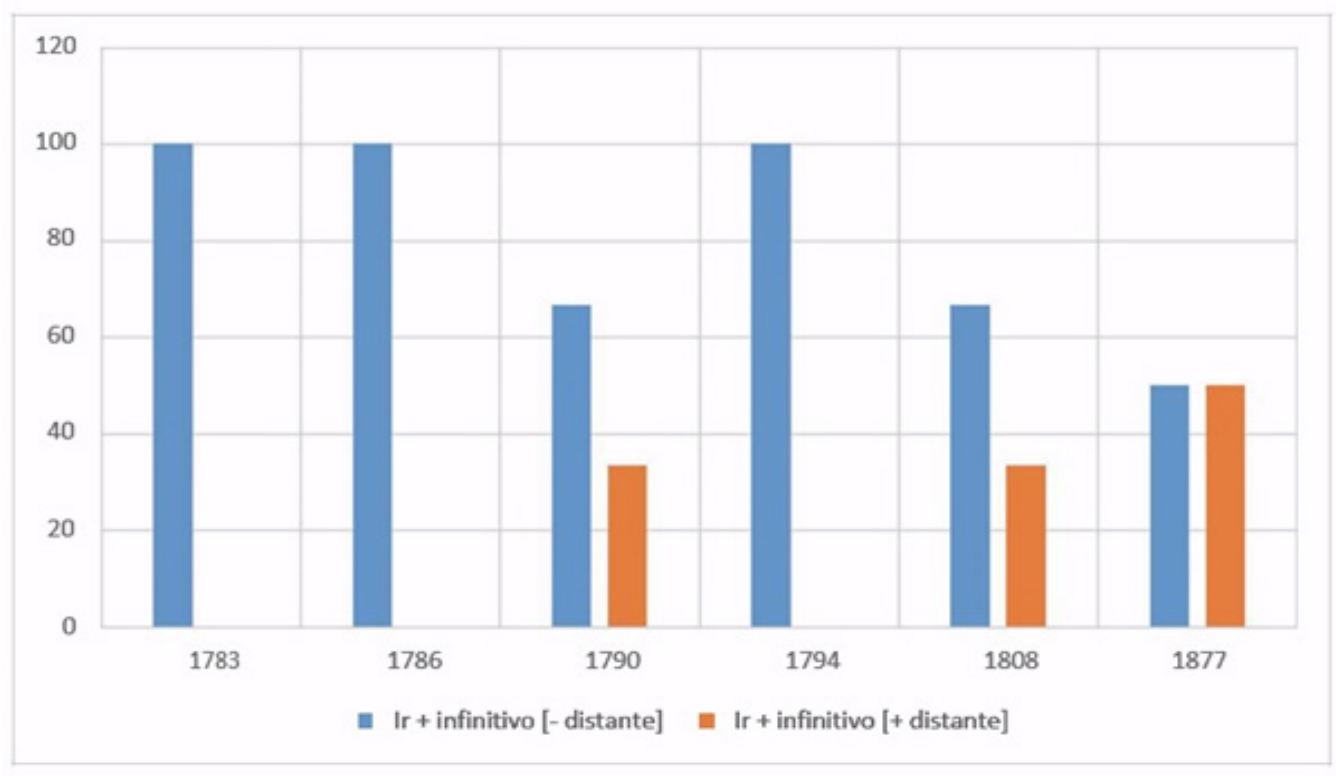

O exemplo (24) traz o verbo ir flexionado no presente do indicativo mais infinitivo. Tal forma foi muito frequente em contextos em que a ação verbal proferida aconteceu em um momento [- distante] em relação ao momento da enunciação. Isso é muito marcado nas peças, pois, logo em seguida de (23), tem-se "Sahe grande quantidade de Rapazes vestidos differentemente, e vaõ beijar a mão a Tiburcio;e depois vaõ-se sentar". Ou seja, o personagem, no momento em que disse (23), já estava executando a ação de ir, já estava saindo. Contrariamente com o que ocorre em (24), em que a proposição ocorre após o momento da fala, num momento [+ distante].

(23) Mas ai que naõ estou em mim, vendo aquelles Estafermos, vou chamar alguns visinhos, que me livrem deste enleio. (T1-1783) [- distante]

(24) Theodorasinha! Vou sonhar comtigo... (T6-1877,;Y23) [+ distante]

Quando analisado o traço de [ \pm futuridade], o Futuro Simples não foi acompanhado de uma expressão de futuridade em $67 \%$ dos casos, enquanto que somente $33 \%$ o foi, (25). Haver/ter de + infinitivo foi acompanhado em $11 \%$ dos casos por [+ futuridade], e $89 \%$ com [- futuridade], (26). Esses dois dados levam a pensar que não é necessária a presença de uma partícula temporal para que o Futuro Simples e Haver/ter de + infinitivo denotem futuro, uma vez que isso já é expresso por si só. 
v. 7 (2)

$132-150$ ago/dez 2017

(25) O Santo Ceo favoreça nossos, constantes extremos, pois por ro rotegidos sempre seremos felices. (P1790) [+ futuridade]

(26) Naõ me faças tambem lagrimijar, por se continuas no choro; posso berrar tanto, que poderei vir a ser soldado; mas dize-me a causa disso? (P1794) [- futuridade]

Tabela 5 - Ir + infinitivo e o traço [ \pm futuridade]

\begin{tabular}{|c|c|c|c|c|c|c|c|c|c|c|c|c|c|c|}
\hline \multirow{3}{*}{ Traço } & \multicolumn{14}{|c|}{ Ir + Infinitivo } \\
\hline & \multicolumn{2}{|c|}{ P1783 } & \multicolumn{2}{|c|}{ P1786 } & \multicolumn{2}{|c|}{ P1790 } & \multicolumn{2}{|c|}{ P1794 } & \multicolumn{2}{|c|}{ P1808 } & \multicolumn{2}{|c|}{ P1877 } & \multicolumn{2}{|c|}{ Total } \\
\hline & $\mathrm{N}^{\mathrm{O}}$ & $\%$ & $\mathrm{~N}^{\mathrm{O}}$ & $\%$ & $\mathrm{~N}^{\mathrm{O}}$ & $\%$ & $\mathrm{~N}^{\mathrm{O}}$ & $\%$ & $\mathrm{~N}^{\mathrm{O}}$ & $\%$ & $\mathrm{~N}^{\mathrm{O}}$ & $\%$ & $\mathrm{~N}^{\mathrm{O}}$ & $\%$ \\
\hline [+ futur. $]$ & 0 & 0 & 0 & 0 & 0 & $\mathrm{O}$ & 0 & 0 & 0 & 0 & 1 & 6 & 1 & 3 \\
\hline [-futur.] & 7 & 100 & 4 & 100 & 6 & 100 & 2 & 100 & 3 & 100 & 15 & 94 & 37 & 97 \\
\hline Total & 7 & 100 & 4 & 100 & 6 & 100 & 2 & 100 & 3 & 100 & 16 & 100 & 38 & 100 \\
\hline
\end{tabular}

A Tabela 5 evidencia que ir + infinitivo também não foi acompanhado por uma partícula temporal em 97\% dos casos, restando somente $3 \%$ em que fora acompanhado. Respectivamente, seguem os exemplos:

(27) Vou ver a minha adorada Lesbia, para alliviar este coraçaõ das saudades que padece. (P1790) [- futuridade]

(28) Descanço um instantinho, e depois vou pôr-me ao brazeiro. (P1877) [+futuridade]

A partir do exemplo (28), fica muito claro que (i) uma ação ocorre no presente (em relação ao momento da fala): "descanso um instantinho"; e que (ii) em seguida (depois) outra ação acontecerá (pôr-me ao braseiro). Assim, (28) traz um exemplo quanto à projeção de futuro do ir + infinitivo [+ distante] acompanhado de uma partícula temporal [+ futuridade].

Pelos resultados das Tabelas 5 e 6, decidiu-se por cruzar os traços [ \pm distante] e [ \pm futuridade] na Tabela 7 , a fim de observar se para 0 ir + infinitivo trazer uma ideia de futuro, [+ distante], é necessária a presença de uma partícula temporal de futuro, uma vez que tal estrutura é formada por um verbo no presente, vou + infinitivo. 
Tabela 6 - Cruzamento de [ \pm futuridade] com [ \pm distante $]$

\begin{tabular}{|c|c|c|c|c|c|c|c|c|c|c|c|c|c|c|c|}
\hline Traços & \multicolumn{15}{|c|}{ Ir + Infinitivo } \\
\hline \multirow{2}{*}{$\begin{array}{l}\text { [t } \\
\text { futur.] }\end{array}$} & \multirow{2}{*}{$\begin{array}{l}\text { [ } \\
\text { dist.] }\end{array}$} & \multicolumn{2}{|c|}{ P1783 } & \multicolumn{2}{|c|}{ P1786 } & \multicolumn{2}{|c|}{ P1790 } & \multicolumn{2}{|c|}{ P1794 } & \multicolumn{2}{|c|}{ P1808 } & \multicolumn{2}{|c|}{ P1877 } & \multicolumn{2}{|c|}{ Total } \\
\hline & & $\mathrm{N}^{\mathrm{O}}$. & $\%$ & $\mathrm{~N}^{\mathrm{O}}$ & $\%$ & $\mathrm{~N}^{\mathrm{O}}$ & $\%$ & $\mathrm{~N}^{\mathrm{O}}$ & $\%$ & $\mathrm{~N}^{\mathrm{O}}$ & $\%$ & $\mathrm{~N}^{\mathrm{O}}$ & $\%$ & $\mathrm{~N}^{\mathrm{O}}$ & $\%$ \\
\hline \multirow{2}{*}{ [+futur $]$} & $\begin{array}{l}{[+} \\
\text { dist.] }\end{array}$ & 0 & 0 & 0 & 0 & 0 & 0 & 0 & $\mathrm{O}$ & 0 & 0 & 1 & 6 & 1 & 3 \\
\hline & $\begin{array}{l}{[-} \\
\text { dist. }]\end{array}$ & 0 & $\mathrm{O}$ & 0 & $\mathrm{O}$ & 0 & 0 & 0 & $\mathrm{O}$ & 0 & 0 & 0 & 0 & 0 & 0 \\
\hline \multirow{2}{*}{ [-futur] } & $\begin{array}{l}{[+} \\
\text { dist.] }\end{array}$ & 0 & 0 & 0 & $\mathrm{O}$ & 2 & 33 & 0 & $\mathrm{O}$ & 1 & 33 & 7 & 44 & 11 & 29 \\
\hline & $\begin{array}{l}{[-} \\
\text { dist. }]\end{array}$ & 7 & 100 & 4 & 100 & 4 & 67 & 2 & 100 & 2 & 67 & 8 & 50 & 26 & 68 \\
\hline Total & - & 7 & 100 & 4 & 100 & 6 & 100 & 2 & 100 & 3 & 100 & 16 & 100 & 38 & 100 \\
\hline
\end{tabular}

Da análise da Tabela 6, pode-se observar que ir + infinitivo [+ distante], ou seja, trazendo uma ideia de futuro, não precisou de uma partícula de projeção futura. Assim, [+ distante] e [+ futuridade] ocorrem em $3 \%$, enquanto que [+ distante] e [- futuridade] ocorrem em $29 \%$ dos casos. Outro dado possível de ser observado é a não necessidade de ir + infinitivo, já como "auxiliar" de futuro, vir acompanhado de uma partícula temporal, pois, mesmo estando no presente (vou fazer), ir + infinitivo [+ distante], expressando [+ futuro], não necessita de [+ futuridade] para expressá-lo. Seguem os exemplos:

(29) Descanço um instantinho, e depois vou pôr-me ao brazeiro. (P1877) [+ futuridade] e [+ distante]

(30) Em quanto temos tempo, vou ver se posso arrombar-lhe o cofre. (P1808) [-furutidade] e [+ distante]

(31) Vou sonhar que não almoçamos, nem ceiamos, nem jantamos... (P1877) [-futuridade] e [+ distante]

(32) Vá buscar quem o ature, coitado, já está mui ginja ; quem me déra já ver o meu querido Mestre, esta paixaõ da muzica me dumina de tal sorte, que apenas ao cravo chego, alli fico embasbacada ; agora vou recordar esta letrinha, que he a moda mais moderna. (P1786) [- futuridade] e [distante]

Observando o Gráfico 4, pode-se depreender que o ir sofreu um processo de reanálise, visto que, até o fim do séc. XVIII (1790), tal estrutura só marcava um traço [-distante], ou seja [+ presente]. 
v. 7 (2)

$132-150$ ago/dez 2017

Porém, é no fim desse mesmo século que haver/ter de + infinitivo, [+ distante], perdeu força no sistema, possibilitando, assim, a entrada de ir + infinitivo [+ distante], [+ futuro].

Gráfico 4 - Reanálise de ir + infinitivo como auxiliar de futuro ao longo do tempo

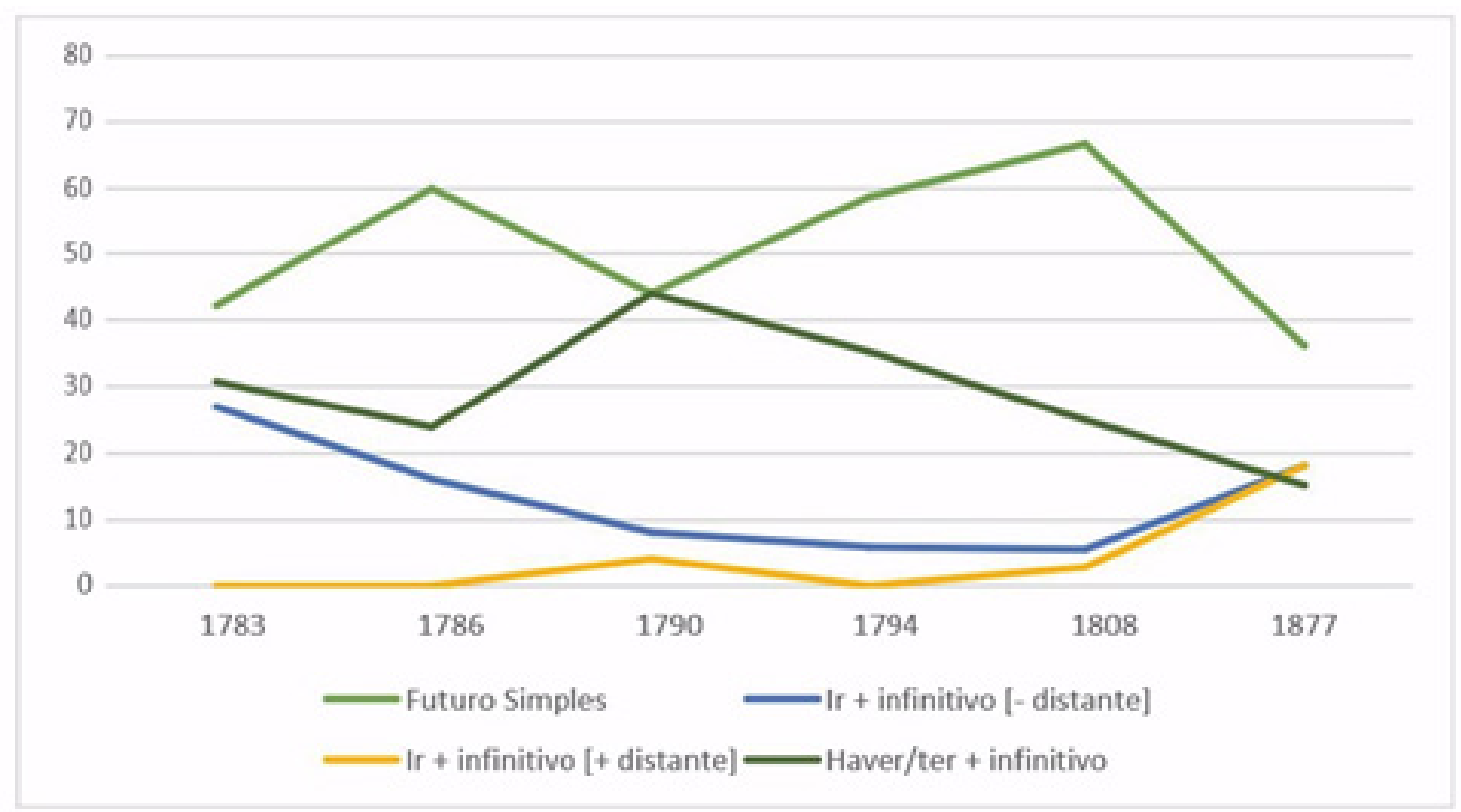

\section{Considerações Finais}

Em geral, os resultados das peças do PE mostraram que ir + infinitivo [+ distante], isto é [+ futuro], apareceu no corpus já em 1790, reaparecendo em 1808 e ganhando força em 1877. Esses dados muito se assemelham aos resultados de Oliveira (2006) para o PB, ao afirmar que, no século XIX, inicia-se o decréscimo da forma de Futuro Simples e o aumento da sua forma concorrente, o ir + infinitivo.

Além disso, os dados do PE também mostram que ir + infinitivo, até 1790 , só era utilizado em contextos [- distante] em relação ao momento da fala, sendo [+ presente]. Posteriormente, assim como no $\mathrm{PB}$, como bem lembra Oliveira (2006), o ir passou por um processo de gramaticalização denotando futuro, pois passou a ter um traço também [+ distante], [+ futuro], passando de uma ideia de movimento locativo e indo para uma ideia de movimento temporal, futuro, também no PE.

Por fim, no que se refere à mudança linguística, a partir da perspectiva da gramática gerativa (cf. CHOMSKY, 1986, 1995; LIGHFOOT, 1991), no português europeu, os dados analisados sugerem que foi no fim do século XIX que a nova geração teve acesso a uma gramática formada por ir + infinitivo, indicativa de futuro. Ou seja, os novos falantes dos séculos 
XIX começaram a fixar regras para a formação de futuro diferentemente da sua geração anterior, tendo como evidência linguística ir + infinitivo [+ distante] e não mais haver + infinitivo e Futuro Simples.

\section{Referências}

ANTONELLI, A.L. Sintaxe da posição do verbo e mudança gramatical na história do português Europeu. 230f. Tese (Doutorado em Linguística). Universidade Estadual de Campinas (Unicamp), Campinas, SP, 2011.

ARAÚJO ADRIANO, P. Â. Alguns aspectos sobre a expressão do futuro no português brasileiro: fala, escrita e representação. Mosaico (São José do Rio Preto), v. 15, p. 493-523, 2016.

Análise da expressão do futuro em textos argumentativos do ProFIS. Lingua, Literatura e Ensino (UNICAMP), v. 9, p. 21-34, 2014.

CHOMSKY, N. Knowledge of Language. Its Nature, Acquisition and Use. New York: Praeger, 1986.

The Minimalist Program, MIT Press, Cambridge, MA, 1995.

FLEISCHMAN, S. The future in thought and language - diachronic evidence from Romance. Cambridge: Cambridge University Press, 1982.

GONÇALVES, A. 0 analitismo verbal e a expressão do futuro no português brasileiro: um estudo diacrônico. Tese (Doutorado em Estudos Linguísticos) - Faculdade de Letras, UFMG, Belo Horizonte, 2013.

GIBBON, A. A expressão do tempo futuro na língua falada de Florianópolis: gramaticalização e variação. 2000. 126 f. Dissertação (Mestrado em Letras/ Linguística). Universidade Federal de Santa Catarina, Florianópolis, 2000.

HRICSINA, J. A evolução do tempo futuro em português é cíclica? Études romanes de Brno, 2011, n. 32/2011, p. 171-180, 2011.

LIGHTFOOT, D. How to Set Parameters: Arguments from Language Change. Cambridge, MA: The MIT Press, 1991.

LIMA, J. P. de. Sobre a gênese e a evolução do futuro com "ir" em português. In: Silva, Augusto Soares da (org.). Linguagem e cognição. Braga: Associação Portuguesa de Linguística / Universidade Católica Portuguesa, 2001.

LOPES, C. R. S. Vossa mercê > você e Vuestra merced > usted: o percurso evolutivo ibérico. Revista de Lingüística da ALFAL, São Paulo, v. 14, p. 173190, 2004 .

OLIVEIRA, F. O futuro em português, alguns aspectos temporais e/ou modais. In Actas do 1. encontro da Associação Portuguesa de Linguística. Lisboa: aPL, p. 353-373, 1985.

OLIVEIRA, J. M. O futuro da língua portuguesa ontem e hoje: variação e mudança. $254 \mathrm{f}$. Tese (Doutorado em Língua Portuguesa). Universidade Federal do Rio de Janeiro, Rio de Janeiro, 2006. 
v. 7 (2) 132-150 ago/dez 2017
A expressão do futuro verbal na escrita jornalística baiana. Linguística (Rio de Janeiro), v. 8, p. 191-209, n, 2012.

ROBERTS, I.; ROUSSOU, A. Syntactic change: a Minimalist approach to grammaticalization. Cambridge: Cambridge University Press, p. 275, 2003.

Recebido em: 31 de ago. de 2016. Aceito em: 26 de dez. de 2016. 